Portland State University

PDXScholar

Summer 8-25-2015

\title{
Upper Body Posture and Pain in Division I Female Volleyball and Softball Athletes
}

Brittany M. Plunkett Castilla

Portland State University

Follow this and additional works at: https://pdxscholar.library.pdx.edu/open_access_etds

Part of the Kinesiotherapy Commons, and the Sports Sciences Commons Let us know how access to this document benefits you.

Recommended Citation

Plunkett Castilla, Brittany M., "Upper Body Posture and Pain in Division I Female Volleyball and Softball Athletes" (2015). Dissertations and Theses. Paper 2536.

https://doi.org/10.15760/etd.2533

This Thesis is brought to you for free and open access. It has been accepted for inclusion in Dissertations and Theses by an authorized administrator of PDXScholar. Please contact us if we can make this document more accessible: pdxscholar@pdx.edu. 
Upper Body Posture and Pain in Division I Female Volleyball and Softball Athletes

$$
\text { by }
$$

Brittany M. Plunkett Castilla

A thesis submitted in partial fulfillment of the

Requirements for the degree of

\author{
Master of Science \\ in \\ Health Studies
}

Thesis Committee:

Gary Brodowicz, Chair

Jim Wallis

Randy Logan

Jonathan Huwe

Portland State University

2015 


\begin{abstract}
Participation in athletics is a popular pastime and form of entertainment. Children often begin to specialize in one sport at a young age in an effort to excel, which increases physical stress and the potential for injuries. Athletes participating in overhead sports are at increased risk of upper body chronic injuries, in part because the shoulder is an unstable hypermobile joint. Posture may also be affected in these athletes because of the demands placed on the upper body. The purpose of this study was to measure the upper body posture in a sample of Division I collegiate volleyball and softball athletes to investigate the prevalence of postural abnormalities and their relationship to pain or injury.
\end{abstract}

Twenty-one Division I collegiate female athletes (seven volleyball; fourteen softball) who participated in their sport during the fall 2014 to spring 2015 seasons were studied. Athletes completed a pain and injury questionnaire, after which individual upper body posture measurements were made. Measurements included resting bilateral scapula position, head position, and shoulder position. An iPad mini camera was used with a commercial application (PostureCo, Inc.) to perform a photographic plumb line posture assessment with photographs taken in anterior, posterior, and lateral views.

Posture analysis revealed a high prevalence $(85.7 \%)$ of forward head posture in this sample. Forward shoulder was noted in $42.9 \%$ of the athletes and abnormal horizontal scapula position appeared to occur more frequently in the dominant arm (71.4 $\%)$ than in the non-dominant arm $(47.6 \%)$. Chi square tests determined that there was no statistically significant relationship between posture abnormalities and self-reported pain 
in this group of athletes. Results of this study—although preliminary—should be used to should inform future research to investigate potential relationships between posture and pain/injury in overhead athletes. 


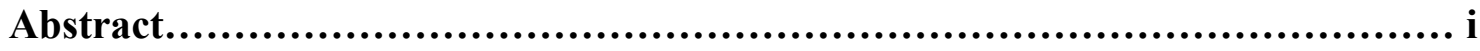

List of Tables.......................................................................... iv

List of Figures................................................................... v

Chapter 1 Introduction.............................................................. 1

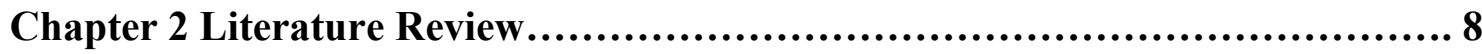

Chapter 3 Methods................................................................ 12

Chapter 4 Results........................................................................ 17

Chapter 5 Discussion \& Conclusion............................................... 21

References.......................................................................... 25

Appendix A: Consent Form...................................................... 27

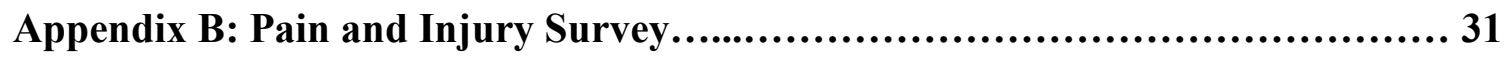

Appendix C: Raw Data............................................................... 35

Appendix D: IRB Approval...................................................... 36 


\section{List of Tables}

Table 1. Subject Characteristics.............................................. 15

Table 2. Head Posture and Pain............................................. 17

Table 3. Shoulder Posture and Pain.............................................. 18

Table 4. Scapula Position and Arm Dominance.................................... 18 


\section{List of Figures}

Figure 1. Sample of Posture Screen............................................... 15

Figure 2. Mean Head Position in Volleyball and Softball Athletes...................... 19

Figure 3. Mean Shoulder Position in Volleyball and Softball Athletes.................. 19

Figure 4. Mean Scapula Position in Volleyball and Softball Athletes.................. 20 


\section{Chapter 1}

\section{Introduction}

In recent years it has become common for young athletes to specialize in one sport at a very young age in an effort to excel and eventually participate as a Division I collegiate athlete. This can be seen across multiple sports such as basketball, football, volleyball, softball and soccer. Such specialization often requires these young athletes to play a particular sport year-round. This increased demand on the body can increase the likelihood of injury and chronic pain that may negatively affect the athlete's future quality of life. Additionally, volleyball and softball are both considered non-contact sports that are unique in that they can place excessive demands on the shoulder.

There is a high prevalence of chronic injuries in overhead sports (Beneka, Malliou, Tsigganos, Gioftsidou, Michalopoulou, Germanou, \& Godolias, 2007). Tennis, softball and volleyball are all considered non-contact overhead sports. Each requires adequate range of motion and strength of the shoulder muscles. The shoulder joint is an unstable joint that attaches to the axial skeleton by the sternoclavicular joint and relies on musculature for stability (Starkey, Brown, \& Ryan, 2010). The shoulder's bony anatomy includes the sternum, clavicle, scapula, and humerus. Some key muscles that provide movement and stability of the shoulder are the latissimus dorsi, rhomboid major and minor, levator scapulae, trapezius, pectoralis major and minor, biceps brachii, deltoid, infraspinatus, supraspinatous, subscapularis, and teres major and minor. Due to the high demand of range of motion and strength in the shoulder it "is predisposed to overuse conditions, especially in individuals participating in activities that require repeated overhead movements" (Starkey, Brown, \& Ryan, 2010, p. 615). 


\section{Volleyball}

A volleyball team is composed of several positions that require specific skills and place a variety of demands on the athletes. However, all volleyball players require good shoulder range of motion and strength for serving, blocking, and attacking. Each member of the team has a specific role that will require varying degrees of overhead motion. The libero performs the fewest number of overhead actions, and is typically the best defensive player on the court, positioned in the back row. An outside attacker tries to score most of the points with precise attacking of the ball so that it hits the ground of the opponent's side. The middle attacker/blocker makes fewer overhead arm swings compared to the outside attacker, but require greater arm velocity and power in performing this action. The setter is a key player for scoring points. The setter's arms are typically above the head, and the neck is extended to keep the eyes focused on the ball. They use two hands to place the ball where needed for the attacker.

Compared to their teammates, athletes who are outside attackers and middle attackers will have an increased demand on their upper body. These athletes require endurance, strength, and power. During an attack, the shoulder is required to be extended and flexed rapidly for the attacker to jump. Once in the air, the attacker's dominant arm is flexed, horizontally abducted, and externally rotated at its fullest range of motion. As the athlete attempts to make contact with the ball, the shoulder must quickly and powerfully horizontally adduct, internally rotate, and extend through the swing. These movements are performed with every swing many times during practice and competition. Outside attackers suffer more injuries compared to other positions (e.g., 38.7 percent versus 27.4 percent in middle attackers) (NCAA, 2010). A volleyball athlete at the Division I level 
regularly performs more than one hundred swings a day for most of the year. This places specific demands on the shoulder joint, which may result in muscle length changes that could presumably affect posture and muscular strength.

\section{Softball}

Another overhead sport is softball. Instead of hitting a ball like a volleyball player, softball athletes perform the overhead motion in order to throw the ball. This requires adequate shoulder range of motion, strength and power. All softball positions require the ability to execute a cocking phase during the throwing mechanics, which requires adequate external rotation and abduction (Bogenschutz, Smith, \& Warden, 2011). There is less shoulder flexion in softball compared to volleyball. Pitchers must also be able to perform an underarm windmill motion in order to pitch the ball to the batter. This requires full motion and control of the shoulder in the sagittal plane.

Windmill pitching requires considerable force from the shoulder and elbow, making both joints susceptible to overuse injuries (Rojas, Provencher, Bhatia, Foucher, Bach, Romeo, Wimmer, \& Verma, 2009).

Softball positions can be classified as infield or outfield. The outfield positions include a right fielder, center fielder and left fielder that catch fly balls and deep line drives. They need to be able to throw long distances accurately. The infield consists of the pitcher, first baseman, second baseman, third baseman, and the shortstop. Infielders must be able to quickly throw the ball fast and accurately. Pitchers may throw more than eighty underhand pitches in practices and games. This underhand motion often results in such fatigue that a relief pitcher must replace the starting pitcher near the end of softball games. 
There is a relatively high prevalence of acute and chronic injuries in softball. Softball is "...the third leading cause of sports injury hospitalizations, behind basketball and football" (Pollack, Canham-Chervak, Gazal-Carvalho, Jones, \& Baker, 2005, p. 277). Injuries that require hospitalizations are usually fractures due to an impact or load. In one study, forty-five percent of injuries resulting in time-loss were to the shoulder and elbow (Rojas et al., 2009). This study did not address the high prevalence of acute injuries in softball, but rather chronic upper body injuries and pain that may be associated with posture adaptations. There is clinical understanding that adaptations of the body occur in overhead athletes because of the mechanics (Bogenschutz et al., 2011). This adaptation is hypothesized to be associated with an athlete's posture.

\section{Posture}

Posture is defined as "the position of the body at a given point in time" (Starkey, Brown, \&Ryan, 2010, p. 95). Proper posture is important because it minimizes the stress on the body, which could improve performance. Proper posture requires the muscles to have an appropriate length, and adequate strength and endurance. When the length and tension relationship is disrupted, posture is affected. "Posture plays both direct and indirect roles in the onset of overuse injuries" (Starkey, Brown, \& Ryan, 2010, p. 100). Assessment of posture can help identify dysfunction or reasons for pain. A posture assessment can be conducted while the subject is standing, sitting or performing locomotor movements such as walking and running. It can also be evaluated from more than one view. Ideally, a posture assessment should be conducted in anterior, posterior and lateral views. A posture assessment can require tools such as a plumb line, goniometer, ruler, camera, or radiograph. When assessing posture with a plumb line, 
radiograph or camera, there are several landmarks that help identify deviations from normal. Some key landmarks include the lateral malleoli, patellae, anterior superior spine of the iliac crest, posterior superior spine of the iliac crest, spinous process of the spine, medial borders of the scapula, acromion process, auditory meatus, and nasal bone (Starkey et al., 2010).

Athletes that require a high demand on specific body parts will often have some sort of postural abnormality. Most human beings have some sort of adaptive postural abnormality that will go unnoticed and cause no pain (Starkey et al., 2010). Some common postural deviations are anteriorly tilted hips, lordotic and kyphotic curvatures of the spine, forward shoulders and forward head. In overhead athletes, these deviations may cause decreased performance and pain or injury.

\section{Pain and Injuries}

An injury is defined by the NCAA as an event that occurred during participation in organized intercollegiate sport that requires medical attention from an athletic trainer or physician (NCAA, 2010). During the 2004 to 2009 volleyball seasons the NCAA reported 21.3 percent upper limb injury occurrences and 17.1 percent of all injuries were overuse injuries (NCAA, 2010). Some upper body chronic injuries seen in overhead athletes are rotator cuff pathology, which includes shoulder impingement and rotator cuff tendinopathy. Another common injury is glenohumeral instability (Starkey et al., 2010; Michener et al., 2003). “The upper extremity, primarily the shoulder region, is at risk of overuse injuries because of the amount of overhead motion required in the sport" (NCAA, 2010). Shoulder injuries are painful, and require rest and rehabilitation. 


\section{Purpose}

The purpose of this study was to measure posture in Division I female volleyball and softball players, and determine whether postural abnormalities are associated with upper body pain or injury.

\section{Significance}

There is little published research documenting volleyball and softball athletes' upper body posture and its relationship to pain. This study assessed whether upper body postural abnormalities are related to pain in these athletes (i.e., Are certain sports at a higher risk for postural abnormalities and pain?). This research may increase understanding about the posture-pain relationship and assist in developing prevention programs designed to decrease the prevalence of chronic injuries.

\section{Hypothesis}

It was hypothesized that participants with previous or current significant pain or injury would have posture abnormalities, which would include forward shoulder and forward head. It was also hypothesized that a greater severity of deviation from normal posture would be associated with participants reporting significant pain.

\section{Definitions}

Overhead Athlete: A collegiate individual participating in a sport that requires an upper arm and shoulder motion.

Posture: The position of the axial skeleton in space.

Photogrammetry: The use of photographs to make measurements and collect data. Orthoposition: A standardized procedure performed prior to data collection in order to obtain a natural standing posture. 


\section{Delimitations and Limitations}

This study was delimited to Division I female volleyball and softball athletes attending Portland State University from the fall 2014 to spring 2015. Female athletes were chosen because Portland State University has a greater number of female overhead athletes than male overhead athletes. However, the relatively small sample size is also a limitation, especially if the prevalence of postural abnormalities and/or injuries and pain are rare.

\section{Assumptions}

It was assumed the student-athletes would comply with all instructions and complete the pain survey honestly. It was assumed that the Posture Screen application is a valid and reliable instrument for posture assessment. It was assumed that the investigator properly and consistently measured the subjects' posture and recorded/analyzed the data correctly. 


\section{Chapter 2}

\section{Literature Review}

\section{Posture}

Posture affects nearly every human being; it is a consequence of the body holding itself up against gravity. "Normal posture, as defined by Kendall and McCreary, is a vertical line passing through the lobe of the ear, the seventh cervical vertebrae, acromial process, greater trochanter, passes anterior to the midline of the knee, and slightly anterior to the lateral malleolus" (Griegel-Morris, Larson, Meuller-Klaus, \& Oatis, 1992, p. 426-427). When a body is not in proper alignment it is considered a postural abnormality. Previous research has supported that increased postural abnormalities can cause pain and injuries (Griegel-Morris et al., 1992; Jong-Hyuck, Jae-Seop, Heon-Seok, Yong-Wook, Oh-Yun, \& Chung-Hwi, 2009). However, there is also research showing that individuals with postural abnormalities can be asymptomatic (Griegel-Morris et al., 1992). There is a relationship between neck posture and shoulder pain, because a forward head posture can cause pain in the neck, which usually leads to a forward shoulder posture to correct the deviation from midline (Jong-Hyuck et al., 2009). Rounded or forward shoulder posture is also a common postural abnormality (Jong-Hyuck et al., 2009; Greenfield, Catlin, Coats, Green, McDonald, \& North, 1995).

\section{Injuries among Volleyball and Softball}

Anecdotal reports from collegiate athletic trainers suggest that forward shoulder and head postures are common among overhead athletes. In particular, volleyball and softball athletes must have adequate range of motion of the shoulder, and sufficient strength and power in order to perform well. Amateur volleyball and softball athletes 
have a high incidence of ankle sprains and lower body fractures (Beneka, Malliou, Tsigganos, Gioftsidou, Michalopoulou, Germanou, \& Godolias, 2007; Pollack, CanhamChervak, Gazal-Carvalo, Jones, \& Baker, 2005; Zetou, Malliou, Lola, Tsigganos, \& Godolias, 2006), and there is good evidence-based research for treatment of acute ankle sprains and fractures. The treatment of these lower body injuries is well-known, while less is known about upper-body injuries in these athletes. Therefore, this study focused on chronic shoulder injuries in high level athletes. Elite and more skilled athletes are more likely to have chronic and overuse type injuries (Beneka et al., 2007; Forthomme, Wieczorek, Frisch, Crielaard, \& Croisier, 2013). According to Forthomme et al. (2013) and Zetou et al. (2006), athletes that have had a previous history of shoulder pain or injury are at an increased likelihood of presenting with a more forward shoulder posture, increasing their probability of shoulder injury. Volleyball athletes playing the attacker position have been shown to be at high risk for shoulder pain, and present with forward shoulder posture (Zetou et al., 2006; NCAA, 2010). The attacker takes the most swings and makes the most contact with the ball. They are an essential part to the offense of a team. In softball, pitchers perform a windmill motion to pitch and therefore are more likely to present with a posture abnormality and pain in the upper extremity. This position also performs this motion excessively (Bogenschutz et al., 2011).

Volleyball and softball athletes have different demands placed on the dominant arm compared to the non-dominant arm. In volleyball, the non-dominant arm rarely has overhead contact with the ball unless one is blocking at the volleyball net. This unilateral demand from one side of the body could have an effect on the natural posture because of muscle length differences and the power needed to perform well. A volleyball or softball 
athlete's dominant arm typically presents with a lower shoulder height, a more forward shoulder, and a scapula that is more abducted when compared to the non-dominant side (Forthomme et al., 2013). This can be explained by the need to have a hypermobile shoulder joint, and eccentrically strong anterior shoulder muscles, which may result in anterior muscle shortening, whereas the posterior muscles are weaker and chronically stretched.

\section{Posture Assessment}

Posture assessments are commonly performed when evaluating the asymmetry of the body in relation to pain and injuries. Since there is a high incidence of chronic shoulder pain in volleyball and softball athletes, it may be helpful to perform posture assessments to determine whether posture is related to the pain.

There are a variety of tools for assessing posture. The common tools used are plumb lines, photogrammetry, goniometry, and flexible rulers (Griegel-Morris et al., 1992; Greenfield et al., 1995; Forthomme et al., 2013; Starkey et al., 2010; Watson, 2001; Ruivo, Pezarat-Correia, \& Carita, 2015; Hennessy \& Watson, 1993). The use of photogrammetry allows posture to be recorded for future reference. It also provides a visual aid for the patient. The use of photogrammetry can also include postural software programs that can increase the validity and reliability of measurements and improve the analysis of the posture.

Other methods of assessing posture include x-rays and specific computer programs (Greenfield et al., 1995; Starkey et al., 2010). These methods are more expensive and therefore not as readily available. They also require specially trained 
personnel to administer the assessment. These tools are not often used in a clinical setting because of the expensive equipment needed and requirement for trained personnel.

The athletic population has a high prevalence of both acute and chronic injuries. Division I volleyball and softball athletes are athletes who often present with a high occurrence of chronic shoulder injuries such as impingement and rotator cuff tendinopathy (Starkey et al, 2010; Michener, McClure, \& Karduna, 2003). There is little published research documenting volleyball and softball athletes' upper body posture and its relationship to pain or injury. Therefore, the purpose of this study was to measure posture in Division I female volleyball and softball players and determine if postural abnormalities in these athletes are common, and whether there is a relationship between upper body posture and neck and shoulder pain. This study also examined whether there were postural differences in athletes participating in these sports. 


\section{Chapter 3}

\section{Methods}

\section{Subjects}

Twenty-one female, Portland State University (PSU) Division I volleyball and softball participants between the ages of 18 and 22 years participated in the study. PSU women's volleyball and softball teams were contacted regarding participation in the study via email and verbal informal contact. When a student athlete agreed to participate in the study, a day and time was arranged for the student athlete to meet individually with the investigator for data collection. Of the 32 available student athletes, 26 responded, 24 met with the investigator, and 21 (7 volleyball; 14 softball) were included in the study. Table 1 presents the descriptive data for the sample. Subjects were excluded if they had surgery of the spine, shoulder or neck within the previous year, a history of disc herniation, or structural scoliosis. Three volleyball athletes were excluded from this study. There were no ethnic or cultural restrictions. Approval was obtained from the Human Subjects Research Review Committee at Portland State University, and informed written consent was obtained from all subjects prior to testing. Subjects were also given the opportunity to provide written consent for the use of photographs taken for posture assessment; all but two provided consent.

\section{Procedure and Materials}

The investigator met each subject in a private, lockable room in the Peter Stott Center on the PSU campus that had adequate lighting and bare walls. The investigator first obtained written informed consent (Appendix A), followed by each subject completing a pain and injury survey (Appendix B). The first page requested demographic 
information and included questions that allowed the determination of eligibility for the study. The remainder of the survey addressed questions concerning current neck and shoulder pain, prior orthopedic surgeries, and prior significant non-surgical injuries. The survey was placed in a folder, separate from all other paperwork. The investigator did not look at the completed surveys until the commencement of data analysis.

For the photographic postural assessment, participants wore spandex shorts and sports bras so that accurate measurements could be made. Height was measured to the nearest 0.5 centimeter and body mass was measured to the nearest 0.1 kilogram. Resting horizontal scapular position (i.e., amount of protraction/ retraction) was then measured according to the procedures outlined in Starkey et al. (2010). A flexible ruler was used while the subject stood comfortably, facing away from the investigator. Horizontal scapular position was obtained by measuring the distance from the $\mathrm{T} 3$ spinous process to the medial border of the scapula; measurements were made to the nearest $0.5 \mathrm{~cm}$. A normal position was defined as a measurement in the range of 5-7 cm; an abnormal position was defined as a scapula being protracted $(>7 \mathrm{~cm})$ or retracted $(<5 \mathrm{~cm})$ in the horizontal plane (Starkey et al., 2010). Both left and right scapulae were measured.

The participant was then asked to stand in the middle of the room so that colored adhesive stickers could be placed on the landmarks needed for the posture assessment. The anterior landmarks were bilateral pupils, center of the lips, bilateral acromion processes, the jugular notch, bilateral $8^{\text {th }}$ ribs, anterior superior iliac spines, and mid ankles. Lateral landmarks were the auditory meatus, acromion process, greater trochanter, mid-knee, and just anterior to the lateral malleoli. Posterior landmarks were bilateral lobes of the ears, $\mathrm{C} 7$, bilateral acromion processes, spinous process of $\mathrm{T} 4, \mathrm{~T} 8, \mathrm{~T} 12$, and 
L3, bilateral T8 ribs, posterior superior iliac spines, and mid ankles. Stickers were placed on all landmarks even though this study involved only upper body posture.

A standing photogrammetry posture assessment was then performed using an iPad mini camera with the Posture Screen application developed by PostureCo, Inc. (Figure 1). Photographic assessments have been shown to be a valid and reliable tool for cervical spine and shoulder analysis (Ruivo et al., 2015; Starkey et al., 2010). Prior to taking each photo, the participants performed a standardized routine to obtain a properly aligned posture (orthoposition). The orthopostion routine required the participant to march in place ten times, roll the shoulders forward and backward three times, nod the head five times, and then inhale and exhale and relax into their normal posture. This has been shown to result in a comfortable and normal posture for the participant (Starkey et al., 2010). After all four photographs were taken, the stickers were removed and the subject was able to leave. Subjects were given the opportunity to request that their personal photograph be e-mailed to them after the completion of the study. 
Brittany Castilla

Portland, OP 97201

19Posturescreen Mobilè

Exam for 8 performed on $4 / 22 / 15$

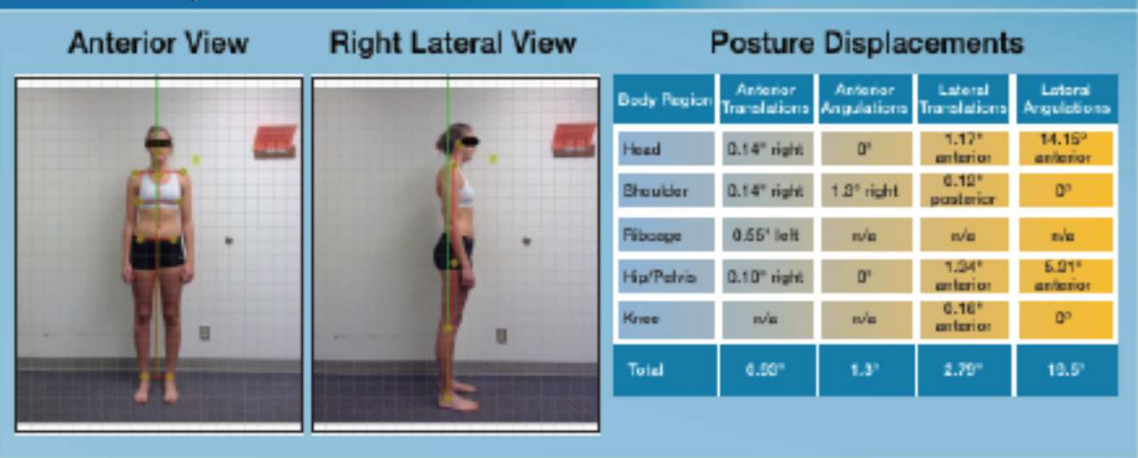

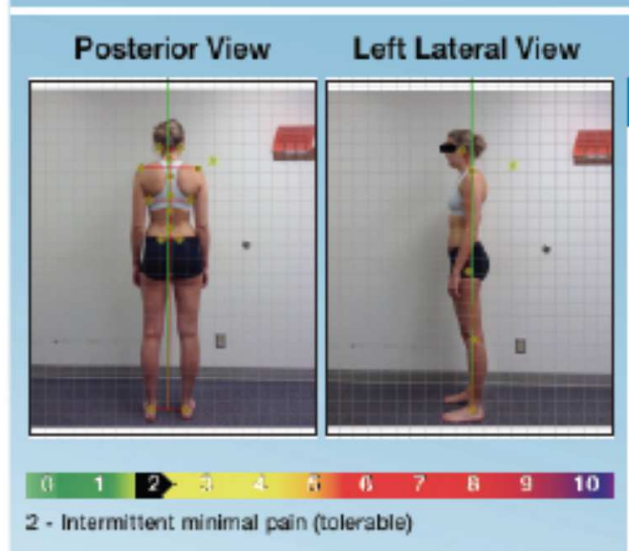

Estimated Efiective Head Weight seccndary to head vs. shoulder posture is $17.8 \mathrm{lbs}$ instead of $12.2 \mathrm{lbs}$

\begin{tabular}{|c|c|c|c|c|}
\hline \multicolumn{5}{|c|}{ Posture Displacements } \\
\hline Bady Rogian | & $\begin{array}{l}\text { Postorior } \\
\text { Irazalelisna }\end{array}$ & $\begin{array}{l}\text { Postoroer } \\
\text { Aajulailana }\end{array}$ & $\begin{array}{l}\text { Lateral } \\
\text { Irazalutisng }\end{array}$ & $\begin{array}{l}\text { Letsera } \\
\text { Araulations }\end{array}$ \\
\hline Head & Q.se" nizk & $10^{\prime}$ ridtit & $\begin{array}{l}2.10^{\circ} \\
\text { anterior }\end{array}$ & $\begin{array}{l}24.71^{\circ} \\
\text { ankerior }\end{array}$ \\
\hline Beutber & Q.AP" right: & $1 . \mathrm{s}^{\mathrm{n}}$ ridtit & $\begin{array}{l}\text { O.e." } \\
\text { muateriar }\end{array}$ & $\begin{array}{l}1.22^{2} \\
\text { mastarior }\end{array}$ \\
\hline Fibecese & $0.18^{\prime}$ leth & nis & nie & wie \\
\hline Hia'Patrie & $0.4 S^{\prime}$ lath & $\sigma^{\prime}$ & $\begin{array}{l}\text { 195: } \\
\text { anterio: }\end{array}$ & $\begin{array}{c}\text { tegs: } \\
\text { anteriour }\end{array}$ \\
\hline Knose & n'e & n'a & $\begin{array}{l}\text { 0.eq* } \\
\text { puatarisar }\end{array}$ & $\begin{array}{l}\text { 1.A4: } \\
\text { prodariut }\end{array}$ \\
\hline T1-T4 & $0.16^{\prime}$ leth & $2.4 \mathrm{~V}$ : & nis & nite \\
\hline T4-TE & $\theta^{*}$ & $\sigma^{\prime}$ & n'e & whe \\
\hline $\mathrm{TB}-\mathrm{T} 12$ & Q.250 right. & $a^{\prime}$ & nis & aik \\
\hline T12 L & Q.s4 iajk & $a^{\prime}$ & n'a & wite \\
\hline La-MdPOE & $0.32^{*}$ nizkt & $2.4 \mathrm{l}$ bी & núk & mite \\
\hline Toial & $1.21^{*}$ & e.y & $4.41^{*}$ & $28.5^{\circ}$ \\
\hline \multicolumn{5}{|c|}{ Averaged Lateral Postural Displacements } \\
\hline & Hoad & Anculter & Herpelus & Kanse \\
\hline $\begin{array}{l}\text { Lateral } \\
\text { Trasalafura }\end{array}$ & $\begin{array}{l}\text { 1.8n" } \\
\text { anterion }\end{array}$ & 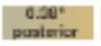 & $\begin{array}{l}1.20^{\circ} \\
\text { anterion }\end{array}$ & $\begin{array}{l}\text { onas" } \\
\text { anterion }\end{array}$ \\
\hline $\begin{array}{l}\text { Lateral } \\
\text { Arevuidions }\end{array}$ & $\begin{array}{l}10.43^{\circ} \\
\text { anteriot }\end{array}$ & 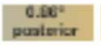 & $\begin{array}{l}\text { 6.07" } \\
\text { anterion }\end{array}$ & $\begin{array}{l}\text { 0.48: } \\
\text { pratarior }\end{array}$ \\
\hline
\end{tabular}

US Patent No. B,721,4567 with other Patents Panding Internationaly O PostureCo, Inc. waw. PesifureAnalysis.com

Figure 1. Sample of Posture Screen. 


\section{Data Analysis}

Prior to data collection, pilot tests were conducted on 3 individuals not involved in the study. This allowed the investigator to practice identifying landmarks and making measurements; it also allowed the investigator to become familiar with the iPad Posture Screen application.

Chi-square tests were used to examine the distribution of data relating selfreported pain with head posture and shoulder posture. Any measurement of the head or shoulder that was greater than one centimeter from zero was considered abnormal (Griegel-Morris et al., 1992). A chi-square test was also used to examine the distribution of data relating scapular position and arm dominance. $\mathrm{P}<0.05$ was used to denote statistical significance for all tests. Data were also examined for each sport separately. 


\section{Chapter 4}

\section{Results}

Subject descriptive data are shown in Table 1. The volleyball athletes appeared to be slightly taller and heavier than the softball athletes, but the mean BMIs were similar. The majority of athletes in each sport were right-arm dominant.

\section{Table 1. Subject Characteristics}

\begin{tabular}{cccccccc} 
& $\mathbf{N}$ & $\begin{array}{c}\text { Age } \\
(\mathbf{y})\end{array}$ & $\begin{array}{c}\text { Height } \\
(\mathbf{m})\end{array}$ & $\begin{array}{c}\text { Mass } \\
(\mathbf{k g})\end{array}$ & $\begin{array}{c}\text { BMI } \\
\left(\mathbf{k g} / \mathbf{m}^{2}\right)\end{array}$ & $\begin{array}{c}\text { DRt } \\
(\mathbf{n})\end{array}$ & $\begin{array}{c}\text { DLt } \\
(\mathbf{n})\end{array}$ \\
\hline VB & 7 & 20.0 & 1.75 & 75.4 & 24.6 & 6 & 1 \\
& & $(1.6)$ & $(0.08)$ & $(11.4)$ & $(3.0)$ & & \\
\hline SB & 14 & 20.2 & 1.65 & 66.9 & 24.6 & 13 & 1 \\
& & $(1.1)$ & $(0.05)$ & $(9.4)$ & $(3.0)$ & & \\
\hline Total & 21 & 20.1 & 1.70 & 71.2 & 24.6 & 19 & 2 \\
& & $(1.3)$ & $(0.08)$ & $(10.7)$ & $(3.0)$ & & \\
\hline
\end{tabular}

Data = Mean (sd); VB = Volleyball; $S B=$ Softball; DRt = Right Arm Dominant; DLt $=$ Left Arm Dominant

The chi-square for head posture and self-reported pain (Table 2) was not statistically significant $\left(\chi^{2}=0.304 ; p>0.05\right)$, indicating no relationship between head posture and self-reported pain. Of the $85.7 \%$ of the subjects were classified as having an abnormal head posture, only $38.9 \%$ reported pain.

Table 2. Head Posture and Pain

\begin{tabular}{lcc} 
& $(-)$ Pain & $(+)$ Pain \\
\hline Normal $(<1 \mathrm{~cm})$ & 1 & 2 \\
$($ mean $=-0.06 ;$ std. dev. $=0.91)$ & & 7 \\
\hline Abnormal $(>1 \mathrm{~cm})$ & 11 & \\
$($ mean $=2.82 ;$ std. dev. $=1.11)$ & & \\
\hline$\chi^{2}=0.304 ; \mathrm{p}>0.05$ & &
\end{tabular}

The chi-square for shoulder posture and self-reported pain (Table 3) was not statistically significant $\left(\chi^{2}=2.36 ; \mathrm{p}>0.05\right)$, indicating no relationship between shoulder 
posture and self-reported pain. Of the $42.9 \%$ of subjects classified as having abnormal shoulder posture, $33.3 \%$ reported shoulder or neck pain.

Table 3. Shoulder Posture and Pain

\begin{tabular}{lcc} 
& $(-)$ Pain & $(+)$ Pain \\
\hline $\begin{array}{l}\text { Normal }(<1 \mathrm{~cm}) \\
(\text { mean }=-0.23 ; \text { std. dev. }=0.65)\end{array}$ & 6 & 6 \\
\hline $\begin{array}{l}\text { Abnormal }(>1 \mathrm{~cm}) \\
(\text { mean }=2.01 ; \text { std. dev. }=0.95)\end{array}$ & 6 & 3 \\
\hline$\chi^{2}=2.36 ; \mathrm{p}>0.05$ & &
\end{tabular}

The chi-square for scapula position and arm dominance (Table 4) was not statistically significant $\left(\chi^{2}=1.88 ; \mathrm{p}>0.05\right)$, indicating no relationship between shoulder posture and arm dominance. As expected, abnormal horizontal scapula position appeared to occur more frequently in the dominant arm $(71.4 \%)$ than in the non-dominant arm $(47.6 \%)$

Table 4. Scapula Position and Arm Dominance

Non-

\begin{tabular}{lcc} 
& Dominant & Dominant \\
\hline $\begin{array}{l}\text { Normal }(5-7 \mathrm{~cm}) \\
(\text { mean }=6.53 ; \text { std. dev. }=0.54)\end{array}$ & 6 & 11 \\
\hline $\begin{array}{l}\text { Abnormal }(>1 \mathrm{~cm}) \\
(\text { mean }=8.12 ; \text { std. dev. }=1.14)\end{array}$ & 15 & 10 \\
\hline$\chi^{2}=1.88 ; \mathrm{p}>0.05$ & &
\end{tabular}

The data were then separated by sport, and differences in head posture, shoulder posture, and scapula position were examined. Figure 2 shows the mean head position (cm) of volleyball and softball athletes having a head position classified as "normal" and those having a head position classified as "abnormal." The mean head position for volleyball athletes classified as "abnormal" was $0.64 \mathrm{~cm}$ greater than similarly classified softball athletes. 


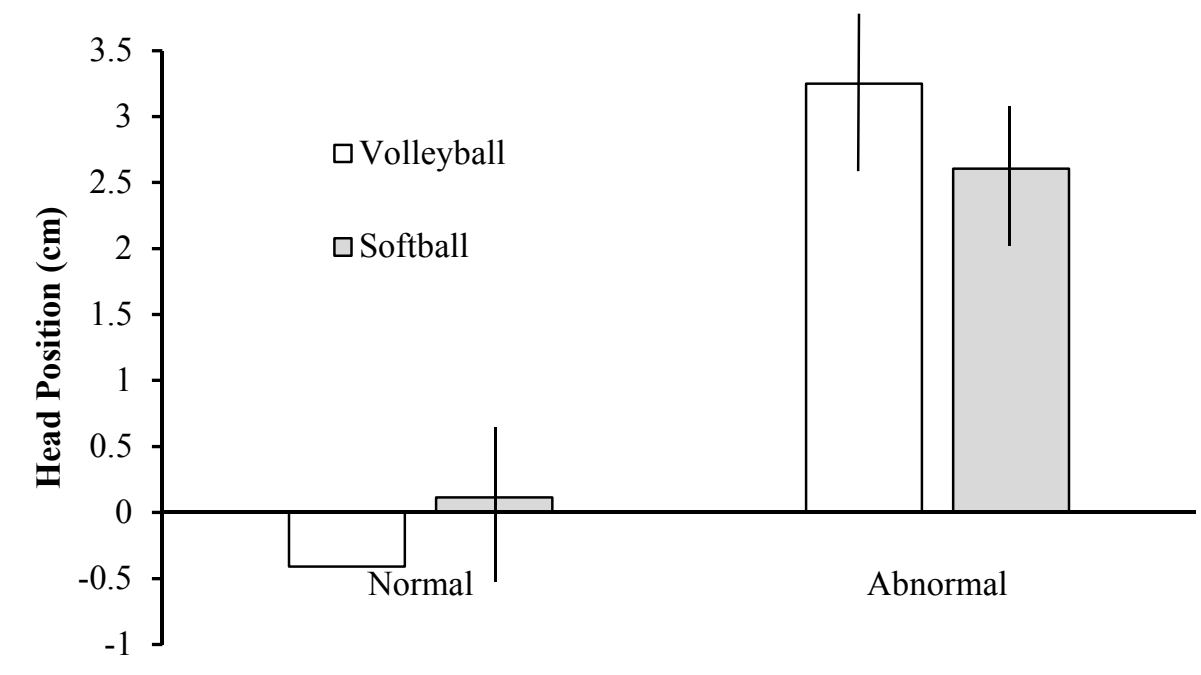

Figure 2. Mean head position in volleyball and softball athletes.

Mean shoulder position $(\mathrm{cm})$ of volleyball and softball athletes having a shoulder position classified as "within normal limits" and those having a shoulder position classified as "abnormal is shown in Figure 3. Values were similar between sports.

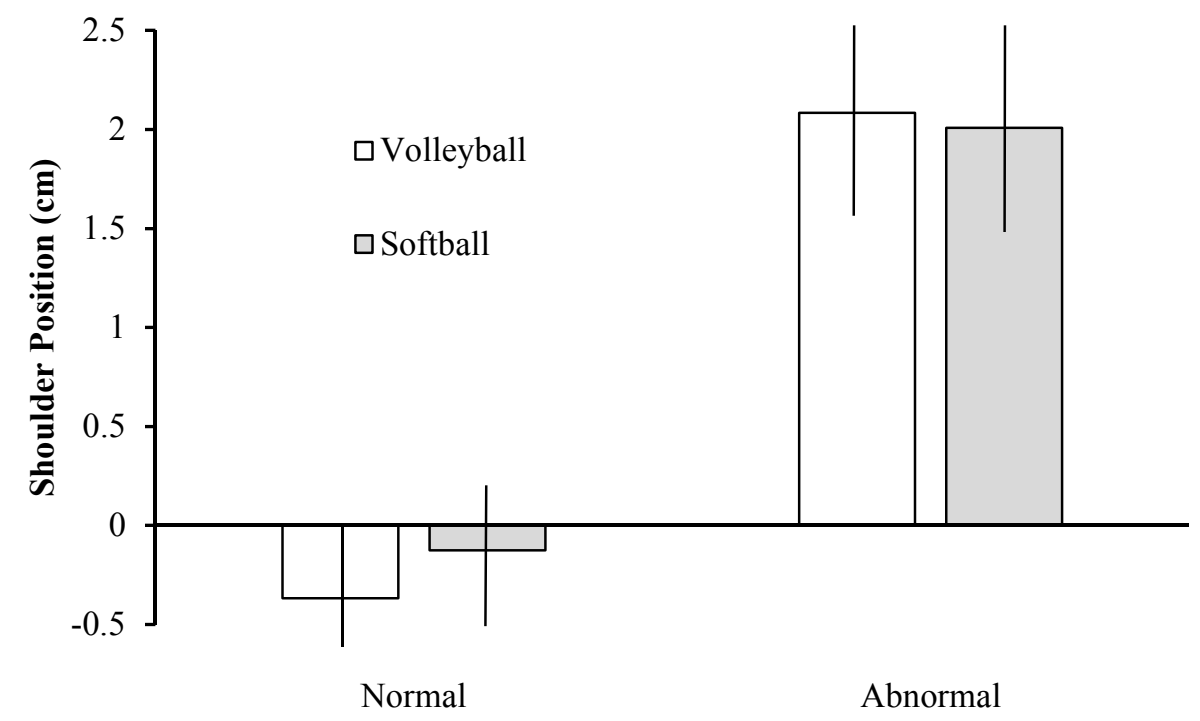

Figure 3. Mean shoulder position in volleyball and softball athletes.

Volleyball athletes exhibited a larger mean difference between those with a shoulder position classified as "within normal limits" than those with a shoulder position 
classified as "abnormal," but magnitudes of the difference for both sports were small. Figure 4 shows the mean horizontal scapula position $(\mathrm{cm})$ for volleyball and softball athletes having scapula position classified as "within normal limits" and those having a scapula position classified as "abnormal." Both the non-dominant and dominant sides are presented.

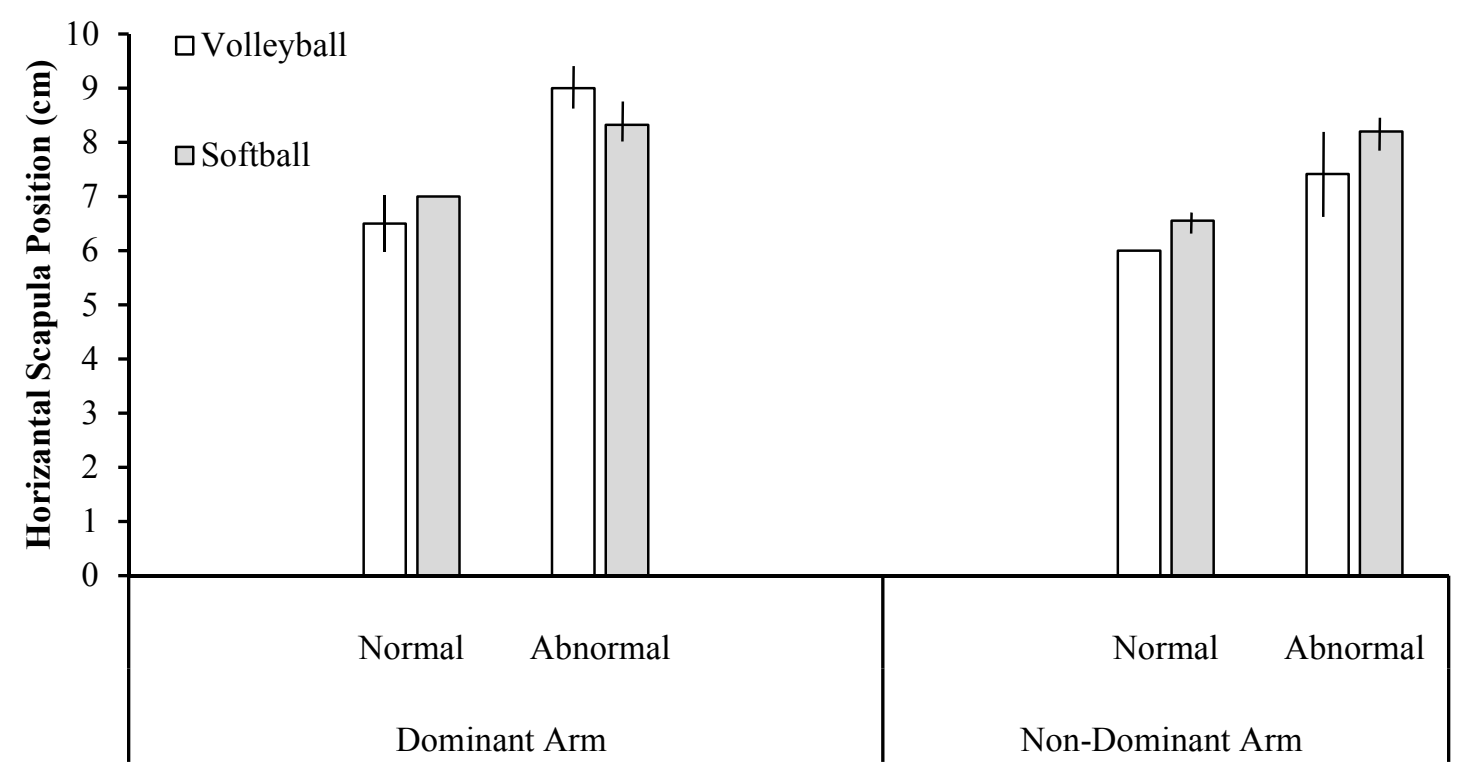

Figure 4. Mean scapula position in volleyball and softball athletes.

Overall, volleyball athletes appear to have a more protracted scapula in their dominant shoulder compared to softball athletes, but the mean difference is small (volleyball $=9 \mathrm{~cm}$; softball $=8.2 \mathrm{~cm}$ ). Additionally, in athletes having a shoulder position classified as "abnormal," the mean difference between dominant and non-dominant scapula position appeared to be slightly larger in volleyball athletes $(1.58 \mathrm{~cm})$ versus softball athletes $(0.13 \mathrm{~cm})$. 


\section{Chapter 5}

\section{Discussion \& Conclusion}

This study assessed the relationship between posture abnormality of the upper body and pain in volleyball and softball athletes. Previous research on chronic pain and posture in overhead athletes is limited.

This study found that forward head posture was common, although there appeared to be no significant relationship with self-reported pain. Eighteen of the twenty-one subjects exhibited a forward head position of greater than one centimeter; five of those subjects exhibited severe forward head posture (greater than four centimeters). This forward head positioning is commonly seen in people who work at desks for long periods, including students. These individuals commonly sit in a slumped position with the eyes directed downward, which results in a shortening of the anterior cervical muscles and a lengthening and weakening of the posterior cervical muscles. A forward head posture was expected in this sample.

Shoulder posture was determined by the Posture Co. application (i.e., average from the lateral view photographs). The application calculated the average of two measurements, using the position of the acromion process in comparison with the head translation and plumb line. As with the head position assessment, a value of greater than one centimeter was considered abnormal. There was no significant relationship between shoulder position and self-reported pain. Some research has claimed it is difficult to differentiate between a forward shoulder position and a rounded upper back using a vertical plumb line, and therefore it has been recommended that shoulder posture be assessed from a horizontal scapular view (Peterson, Blakenship, Robb, Walker, Bryan, 
Stetts, Mincey \& Simmons, 1997). This could be one reason that the shoulder measurements made with the Posture Co. application are different from the horizontal scapular measurements made by the investigator.

In this present study, shoulder pain was not commonly reported. This contradicts the findings presented by Forthomme et al. (2013) and Zetou et al. (2006). Neck pain was reported more frequently than shoulder pain. This was surprising, since these athletes were considered overhead dominant athletes. One explanation for this unexpected result is that only one sport was in-season at the time of analysis. The lower physical demands of a sport in the off-season can decrease or eliminate dominant arm pain. Another potential reason could be that the definition of pain was not consistently reported. Some athletes may have viewed their pain and discomfort as normal, and would not have reported it. It may also be possible that these athletes have adapted to the high demands of their sport, thereby compensating with movements that do not cause pain.

Arm dominance did not appear to affect scapula position (Table 4). However, the dominant arm appeared to be more likely to present with a protracted shoulder (71.4\%) compared to the non-dominant arm (47.6\%). Overhead athletes need adequate range of motion to obtain high enough velocity to either hit the volleyball or throw the softball. The posterior muscles naturally lengthen and the anterior muscles shorten to perform well. The investigator casually observed that most subjects had a lower and more forward shoulder of their dominant arm. This was later confirmed with the horizontal scapula measurements. Horizontal scapula positioning was measured in centimeters and this technique is more accurate than the reliance on a plumb line program to assess 
horizontal scapula positioning from a vertical line (Peterson et al., 1997). A forward shoulder was seen in both arms, but the dominant arm was more consistently protracted.

The data were also examined separately by sport (Figure 2, 3 and 4). Softball and volleyball are both one-arm dominant sports. Figure 2 showed a minor increase in the severity of a forward head posture in volleyball athletes, but the mean difference was only $0.64 \mathrm{~cm}$ compared to softball athletes. Figures 2 and 3 show little to no difference between volleyball and softball athletes' head and shoulder postures. Figure 4 shows the dominant and non-dominant arm scapula measurements between sports. The difference between dominant and non-dominant arms was less than expected. It was hypothesized that the dominant arm would present with a significant resting protraction when compared to the non-dominant arm. The volleyball athletes had a larger mean difference in abnormal scapula protraction between dominant and non-dominant arms $(1.58 \mathrm{~cm})$ than the softball athletes $(0.13 \mathrm{~cm})$. Although not statistically significant in this study, further research with larger sample sizes is warranted.

There are several limitations to this study, which may have affected the results. The greatest limitation was a sample size of only 21 subjects, just 7 of which were volleyball athletes. Of the 32 athletes recruited for this study, only 26 responded; 2 athletes were unable to make the time to participate, and 3 volleyball athletes were excluded due to diagnosed or presumed structural scoliosis. The small sample size limited statistical power.

Another limitation was that the study was performed while volleyball athletes were out-of-season, and softball athletes were in-season. This may have affected how the 
athletes self-reported shoulder pain because of differences in the magnitude and/or frequency of shoulder stress.

Future studies should include a larger sample size to more appropriately evaluate the relationship between pain and upper body posture in overhead athletes. Also, forward shoulder needs to be differentiated from a rounded upper back, which would require additional scapula measurements (Starkey et al., 2010).

\section{Conclusion}

An ideal posture is uncommon, but not unrealistic. Ideal posture is defined so that there is a known standard which to compare to. This is helpful for medical personnel when working with patients. Good posture decreases the amount of loading and stress placed on the body, but takes practice and awareness to obtain. It requires adequate amount of mobility and stability to be able to achieve ideal posture. This study showed that an abnormal upper body posture is common in a sample of overhead athletes, but there appears to be no relationship between upper body posture and shoulder or neck pain. When working with Division I volleyball and softball athletes, athletic trainers should remember that forward head and shoulder posture may be considered normal and not be a cause of pain. 


\section{References}

Beneka, A., Malliou, P., Tsigganos, G., Gioftsidou, A., Michalopoulou, M., Germanou, E., \& Godolias, G. (2007). A prospective study of injury incidence among elite and local division volleyball players in Greece. Journal of Back and Musculoskeletal Rehabilitation, 20(2), 115-121.

Bogenschutz, E. D., Smith, H. D., \& Warden, S. J. (2011). Mid-humerus adaptation in fast pitch softballers and the impact of throwing mechanics. Medicine and Science in Sports and Exercise, 43(9), 1698.

Forthomme, B., Wieczorek, V., Frisch, A., Crielaard, J. M., \& Croisier, J. L. (2013). Shoulder pain among high-level volleyball players and preseason features. Medicine and Science in Sports and Exercise, 45(10), 1852-1860.

Greenfield, B., Catlin, P. A., Coats, P. W., Green, E., McDonald, J. J., \& North, C. (1995). Posture in patients with shoulder overuse injuries and healthy individuals. Journal of Orthopaedic \& Sports Physical Therapy, 21(5), 287-295.

Griegel-Morris, P., Larson, K., Mueller-Klaus, K., \& Oatis, C. A. (1992). Incidence of common postural abnormalities in the cervical, shoulder, and thoracic regions and their association with pain in two age groups of healthy subjects. Physical Therapy, 72(6), 425-431.

Hennessey, L., \& Watson, A. W. (1993). Flexibility and posture assessment in relation to hamstring injury. British Journal of Sports Medicine, 27(4), 243-246.

Michener, L. A., McClure, P. W., \& Karduna, A. R. (2003). Anatomical and biomechanical mechanisms of subacromial impingement syndrome. Clinical Biomechanics, 18(5), 369-379.

National Collegiate Athletics Association. (2010). Women's Volleyball Injuries: Data from the 2004/05-2008/09 Seasons. Retrieved from http://www.ncaa.org/sites/default/files/NCAA_W_Volleyball_Injuries_WEB.pdf.

Oyama, S., Myers, J. B., Wassinger, C. A., Ricci, R. D., \& Lephart, S. M. (2008). Asymmetric resting scapular posture in healthy overhead athletes. Journal of Athletic Training, 43(6), 565.

Peterson, D., Blankenship, K., Robb, J., Walker, M., Bryan, J., Stetts, D., Mincey, L., \& Simmons, G. (1997). Investigation of the validity and reliability of four objective techniques for measuring forward shoulder posture. Journal of Orthopeadic \& Sports Physical Therapy, 25(1), 34-42.

Pollack, K. M., Canham-Chervak, M., Gazal-Carvalho, C., Jones, B. H., \& Baker, S. P. (2005). Interventions to prevent softball related injuries: A review of the literature. Injury Prevention, 11(5), 277-281. 
Rojas, I. L., Provencher, M. T., Bhatia, S., Foucher, K. C., Bach, B. R., Romeo, A. A., ... \& Verma, N. N. (2009). Biceps activity during windmill softball pitching injury implications and comparison with overhand throwing. The American Journal of Sports Medicine, 37(3), 558-565.

Ruivo, R. M., Pezarat-Correia, P., \& Carita, A. I. (2015). Intrarater and interrater reliability of photographic measurement of upper-body standing posture of adolescents. Journal of Manipulative and Physiological Therapeutics, 38(1), 7480 .

Starkey, C., Brown, S., \& Ryan, J. (2010). Examination of orthopedic and athletic injuries (Ed. 3. ed.). Philadelphia: F.A. Davis.

Watson, A. W. (2001). Sports injuries related to flexibility, posture, acceleration, clinical defects, and previous injury, in high-level players of body contact sports. International Journal of Sports Medicine, 22(3), 222-225.

Weon, J. H., Oh, J. S., Cynn, H. S., Kim, Y. W., Kwon, O. Y., \& Yi, C. H. (2010). Influence of forward head posture on scapular upward rotators during isometric shoulder flexion. Journal of Bodywork and Movement Therapies, 14(4), 367-374.

Zetou, E., Malliou, P., Lola, A., Tsigganos, G., \& Godolias, G. (2006). Factors related to the incidence of injuries' appearance to volleyball players. Journal of Back and Musculoskeletal Rehabilitation, 19(4), 129-134. 


\title{
Appendix A: Consent Form
}

\author{
The Portland State University \\ Consent to Participate in Research \\ Upper Body Posture and Pain in Division I Female Volleyball and Softball Athletes
}

March 15, 2015

Introduction

You are being asked to participate in a research study that is being done by Gary R. Brodowicz who is the Principal Investigator and Brittany Plunkett Castilla, from the Department of Community Health, at Portland State University (PSU) in Portland, Oregon . This research is studying upper body posture in overhead sports, specifically in PSU volleyball and softball athletes. It will be analyzing the relationship of posture and pain.

You are being asked to participate in this study because you have been identified as a member of the PSU volleyball or softball teams in the 2014 to 2015 season.

This form will explain the research study, and will also explain the possible risks as well as the possible benefits to you. We encourage you to talk with your family and friends before you decide to take part in this research study. If you have any questions, please ask one of the study investigators.

What will happen if I decide to participate?

If you agree to participate, the following things will happen:

A date and time will be scheduled for you to meet with an investigator. During that time the study will be explained and written, informed consent will be obtained. You will then be asked to change clothes to spandex and a tight-fitting shirt in a private and locked room. Your height and weight will then be measured. A questionnaire will then be handed to you to fill out. Once completed the posture analysis will begin. This includes stickers be placed on certain areas of your body, and four pictures be taken from different views, using an iPad mini Posture application. Your images will be password protected so the investigator will be the only one with access to the images until personal identifiers are removed. After taking the images, your shoulder blades will be measured using a ruler. Before leaving the appointment, you will be given a subject number that will be linked to your data and the investigators contact information. If you wish to receive your data, you can email the investigator after the research study is complete with your subject number and your data will be sent to that email address you provided. 
How long will I be in this study?

Participation in this study will take a total of one hour over a period of one appointment.

What are the risks or side effects of being in this study?

There are risks of stress, emotional distress, inconvenience and possible loss of privacy and confidentiality associated with participating in a research study. Participation and the results of the study will not affect your University enrollment or academic status. It will also not affect your position on the team nor your scholarship status. Individual results will remain confidential and unavailable to the general public. If a photograph of the posture analysis picture is eventually submitted for publication in a scholarly journal or presentation, it will have your face obscured with a black bar. All data will remain password protected or in sealed envelopes kept in a secure and locked area. The student investigator making all measurements is a NATA-certified graduate student athletic trainer and is also female. All measurements will be made in a private location.

What are the benefits to being in this study?

You will be able to obtain your individual posture analysis if you contact the investigator after the research study has been defended to the committee, include your subject number. This study will also benefit the Division I population of female volleyball and softball athletes by identifying common posture tendencies and pain/injuries. This may help therapists develop better rehabilitation programs and pre-rehabilitation programs to prevent overuse injuries that may be related to posture. It may also determine whether the posture is common in the overhead sport and if injuries are associated with posture.

How will my information be kept confidential?

We will take measures to protect the security of all your personal information, but we cannot guarantee confidentiality of all study data. Each subject will be provided with a subject identification number. The subject identification number linked to participant names will be secured in a locked file cabinet in a sealed envelope. The investigator will not be viewing the pain and injury section of the survey until the student investigator works to compile the data where your subject number will be the only association to you. All data collected will be password protected or sealed and kept for four years, and then destroyed after July 2019.

Information contained in your study records is used by study staff. The Portland State University Institutional Review Board (IRB) that oversees human subject research and/or other entities may be permitted to access your records, and there may be times when we are required by law to share your information. It is the investigator's legal obligation to report child abuse, child neglect, elder abuse, harm 


\section{to self or others or any life-threatening situation to the appropriate authorities, and;}

therefore, your confidentiality will not be maintained.

Your name will not be used in any published reports about this study.

Unidentifiable photographic images of your posture analysis may be used in presentations or publications. The photograph would have a black bar over the eyes. This would be voluntary.

Will I be paid for taking part in this study? No.

Can I stop being in the study once I begin? Yes.

Your participation in this study is completely voluntary. You have the right to choose not to participate or to withdraw your participation at any point in this study without penalty or loss of benefits to which you are otherwise entitled.

Whom can I call with questions or complaints about this study?

If you have any questions, concerns or complaints at any time about the research study, Gary Brodowicz, or his associates will be glad to answer them at 503.725.5119.

If you need to contact someone after business hours or on weekends, please call 925-8957230 and ask for Brittany Plunkett Castilla.

Whom can I call with questions about my rights as a research participant?

If you have questions regarding your rights as a research participant, you may call the PSU Office for Research Integrity at (503) 725-2227 or 1(877) 480-4400. The ORI is the office that supports the PSU Institutional Review Board (IRB). The IRB is a group of people from PSU and the community who provide independent oversight of safety and ethical issues related to research involving human participants. For more information, you may also access the IRB website at https://sites.google.com/a/pdx.edu/research/integrity.

\section{CONSENT}

You are making a decision whether to participate in this study. Your signature below indicates that you have read the information provided (or the information was read to you). By signing this consent form, you are not waiving any of your legal rights as a research participant. 
You have had an opportunity to ask questions and all questions have been answered to your satisfaction. By signing this consent form, you agree to participate in this study. A copy of this consent form will be provided to you.

Name of Adult Subject (print) Signature of Adult Subject Date

By signing below you are consenting to the posture images taken of you to be used in presentations and publications. Identifying marks will be hidden as best as possible. This option is voluntary, and unneeded to participate in the research study.

$\overline{\text { Name of Adult Subject (print) }} \overline{\text { Signature of Adult Subject }} \overline{\text { Date }}$

\section{INVESTIGATOR SIGNATURE}

This research study has been explained to the participant and all of his/her questions have been answered. The participant understands the information described in this consent form and freely consents to participate.

Name of Investigator/ Research Team Member (type or print)

(Signature of Investigator/ Research Team Member) Date 


\section{Appendix B: Pain and Injury Survey}

Subject \#

\section{Demographic Information}

Please answer each question honestly and to the best of your ability. If you have any questions ask the investigator. Circle each answer that best describes you. For number 5 , 6 and 8 write your answer in the corresponding box.

\begin{tabular}{|c|c|c|c|c|c|}
\hline 1. Age & 18 & 19 & 20 & 21 & 22 \\
\hline 2. Year in School & Freshman & Sophomore & Junior & Senior & $5^{\text {th }}$ Year \\
\hline 3. Handedness & Right & Left & Both & & \\
\hline 4. Sport & Volleyball & Softball & & & \\
\hline $\begin{array}{l}\text { 5. Number of } \\
\text { consecutive years } \\
\text { playing } \\
\text { competitively }\end{array}$ & & & & & \\
\hline 6. Current Position & & & & & \\
\hline $\begin{array}{l}\text { 7. Are you currently } \\
\text { taking medication } \\
\text { for pain? }\end{array}$ & Yes & No & & & \\
\hline $\begin{array}{l}\text { 8. If yes, what injury } \\
\text { or complaint? }\end{array}$ & & N/A & & & \\
\hline $\begin{array}{l}\text { 9. Do you have a } \\
\text { previous history } \\
\text { of scoliosis? }\end{array}$ & Yes & No & $\begin{array}{l}\text { I do not } \\
\text { know }\end{array}$ & & \\
\hline $\begin{array}{l}\text { 10. Have you had } \\
\text { surgery with in } \\
\text { the last } 6 \text { months } \\
\text { requiring physical } \\
\text { therapy? }\end{array}$ & Yes & No & & & \\
\hline
\end{tabular}




\section{Subject \#}

\section{Pain and Injury Survey}

Please answer these questions to the best of your ability. If you have any questions or need explanation, please ask the investigator.

\section{Definitions:}

Orthopedic - Refers to muscles, tendons, ligaments and bones

Acute-Sudden pain that leads immediate loss of function

Chronic-Gradual development of pain that leads to a decrease in function over a long duration of time

1. Do you have current neck or shoulder pain? YES or NO

If you answered no, skip to question 2.

a. Where is your current pain? Place an " $\mathrm{X}$ " on the model below where your pain is.

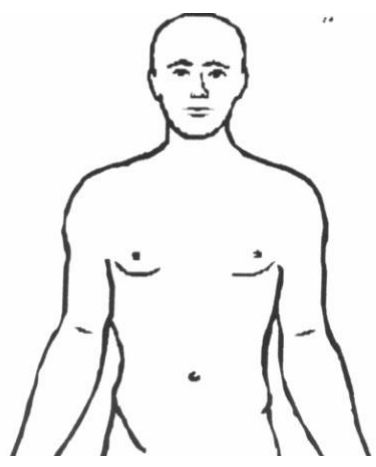

b. How long has it been consistently painful:

c. Rate your current average daily pain for this week using the visual analog below (nearest whole number):

\begin{tabular}{|l|lll|ll|}
\hline No Pain & $\begin{array}{l}\text { Mild, } \\
\text { Annoying } \\
\text { Pain }\end{array}$ & $\begin{array}{l}\text { Nagging, } \\
\text { Uncomfortable } \\
\text { Pain }\end{array}$ & $\begin{array}{l}\text { Distressing, } \\
\text { Miserable } \\
\text { Pain }\end{array}$ & $\begin{array}{l}\text { Intense, } \\
\text { Dreadful } \\
\text { Pain }\end{array}$ & $\begin{array}{l}\text { Worst } \\
\text { Possible, } \\
\text { Excruciating } \\
\text { Pain }\end{array}$ \\
\hline
\end{tabular}




\section{Subject \#}

2. Prior orthopedic surgeries (be specific):

\begin{tabular}{|l|l|}
\hline a. Body Part & \\
\hline b. Date Of Surgery & \\
\hline c. Procedure Done & \\
\hline d. Right or Left & \\
\hline
\end{tabular}

\begin{tabular}{|c|c|}
\hline e. Body Part & \\
\hline f. Date Of Surgery & \\
\hline g. Procedure Done & \\
\hline h. Right or Left & \\
\hline
\end{tabular}

\begin{tabular}{|ll|l|}
\hline i. & Body Part & \\
\hline j. & Date Of Surgery & \\
\hline k. & Procedure Done & \\
\hline 1. & Right or Left & \\
\hline
\end{tabular}

3. Significant non-surgical injuries prior to today's date

\begin{tabular}{|l|l|}
\hline a. Date of Injury & \\
\hline b. Body Part and injury & \\
\hline c. Side & \\
\hline d. Type (Acute or Chronic) & \\
\hline $\begin{array}{l}\text { e. Days missed from practice or } \\
\text { games? }\end{array}$ & \\
\hline $\begin{array}{l}\text { f. Any modifications to activity? } \\
\text { g. If so, for how long? }\end{array}$ & \\
\hline $\begin{array}{l}\text { h. State the date healed or whether } \\
\text { ongoing. }\end{array}$ & \\
\hline
\end{tabular}


Subject \#

\begin{tabular}{|c|c|}
\hline i. Date of Injury & \\
\hline j. $\quad$ Body Part and injury & \\
\hline k. Side & \\
\hline 1. Type (Acute or Chronic) & \\
\hline $\begin{array}{l}\text { m. Days missed from practice or } \\
\text { games? }\end{array}$ & \\
\hline $\begin{array}{l}\text { n. Any modifications to activity? } \\
\text { o. If so, for how long? }\end{array}$ & \\
\hline $\begin{array}{l}\text { p. State the date healed or whether } \\
\text { ongoing. }\end{array}$ & \\
\hline
\end{tabular}

\begin{tabular}{|l|l|}
\hline q. & \\
\hline r. Body of Injury & \\
\hline s. Side & \\
\hline t. Type (Acute or Chronic) & \\
\hline u. Days missed from practice or & \\
$\quad$ games? & \\
\hline $\begin{array}{l}\text { v. Any modifications to activity? } \\
\text { w. If so, for how long? }\end{array}$ & \\
\hline x. State the date healed or whether & \\
\hline
\end{tabular}


Appendix C: Raw Data

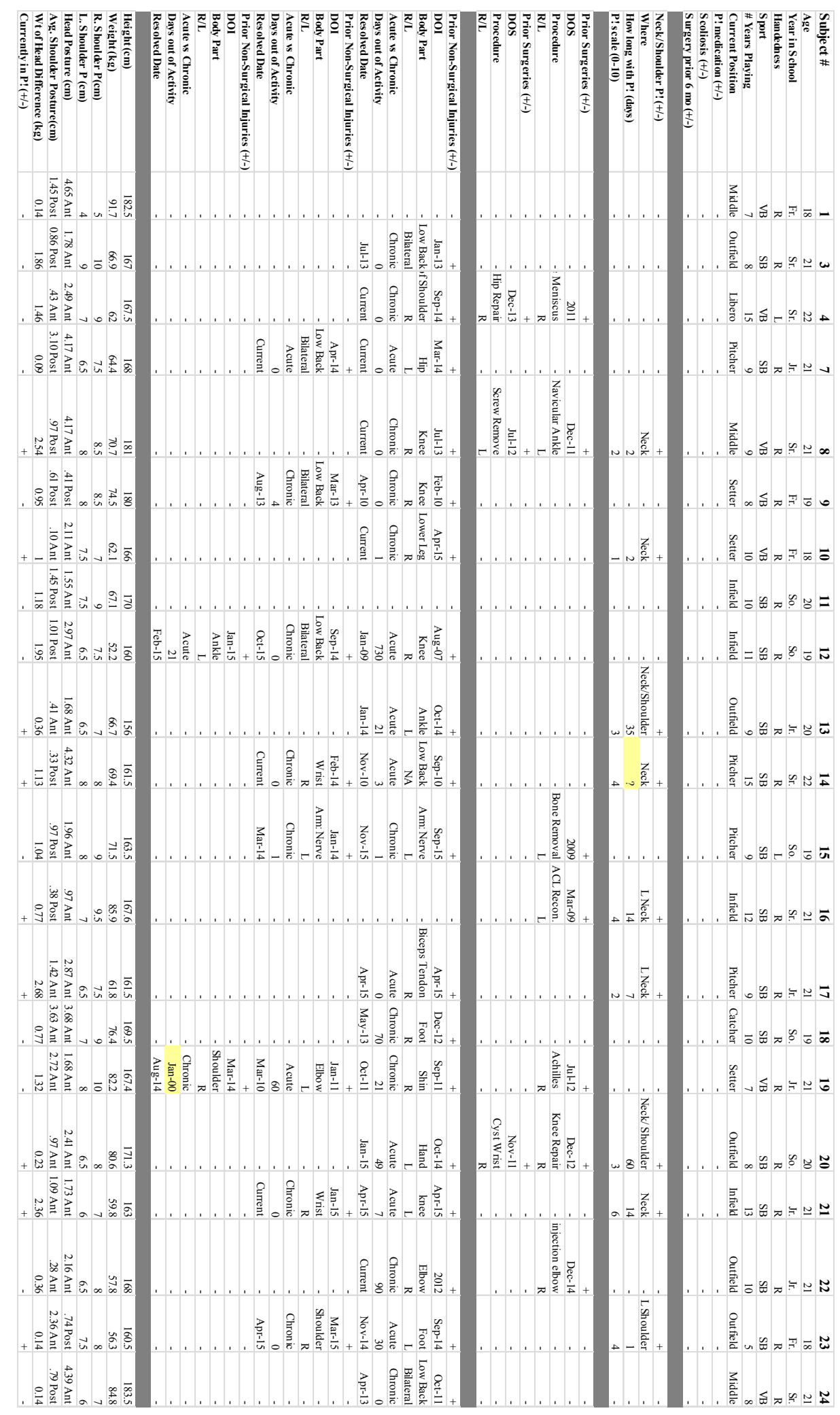


Date: April 22, 2015

\section{Appendix D: IRB Approval}

To: Gary Brodowicz / Brittany Plunkett

From: Karen Cellarius, HSRRC Chair

Re: HSRRC approval for your project titled, "Upper Body Posture and Pain in Division I Female Volleyball and Softball Athletes" HSRRC Proposal \# 153367

Approval-Expiration: April 22, 2015 - March 24, 2016

Notice of IRB Review and Approval-Amendment Expedited Review as per Title 45 CFR

Part 46.110, 63 FR 60366, \# 4, 6, 7

The amendment submitted on 04/11/2015 for the project identified above has been reviewed and approved by the Portland State University Institutional Review Board (IRB) and the Office of Research Integrity using an expedited review procedure. This is a minimal risk study. This approval is based on the assumption that the materials, including changes/clarifications that you submitted to the IRB contain a complete and accurate description of all the ways in which human subjects are involved in your research. This approval is given with the following standard conditions:

1. You are approved to conduct this research only during the period of approval cited below; 2. You will conduct the research according to the plans and protocol submitted (approved copy enclosed); 3. You will immediately inform the Office of Research Integrity of any injuries or adverse research events involving subjects; 4. You will immediately request approval from the IRB of any proposed changes in your research, and you will not initiate any changes until they have been reviewed and approved by the IRB; 5. You will only use the approved informed consent document(s) (enclosed); 6. You will give each research subject a copy of the informed consent document; 7. If your research is anticipated to continue beyond the IRB approval dates, you must submit a Continuing Review Request to the IRB approximately 60 days prior to the IRB approval 
expiration date. Without continuing approval the Protocol will automatically expire on 03/24/2016. Please remember that the IRB office does not send out expiration reminders. Portland State University and the Office of Research Compliance appreciate your efforts to conduct research in compliance with PSU Policy and the Federal regulations that have been established to ensure the protection of human subjects in research. Thank you for your cooperation with the IRB process.

If you have questions or concerns, please contact the Office of Research Integrity at 503725-2227.

Approved: Amended Protocol version 04/11/2015, including change in attire for testing. 